STUDI

FRANCESI

\section{Studi Francesi}

Rivista quadrimestrale fondata da Franco Simone

190 (LXIV | I) | 2020

Varia - fasc. I - gennaio-aprile 2020

\title{
MARILYN MALLIA, Présence du roman gothique anglais dans les premiers romans de George Sand
}

\section{Annabelle M. Rea}

\section{(2) OpenEdition}

\section{Journals}

\section{Édition électronique}

URL : https://journals.openedition.org/studifrancesi/22926

DOI : $10.4000 /$ studifrancesi.22926

ISSN : 2421-5856

\section{Éditeur}

Rosenberg \& Sellier

\section{Édition imprimée}

Date de publication : 1 avril 2020

Pagination : 197

ISSN : 0039-2944

\section{Référence électronique}

Annabelle M. Rea, « MARILYN malLIA, Présence du roman gothique anglais dans les premiers romans de George Sand », Studi Francesi [En ligne], 190 (LXIV | I) | 2020, mis en ligne le 01 mai 2020, consulté le 03 août 2021. URL : http://journals.openedition.org/studifrancesi/22926 ; DOI : https://doi.org/10.4000/ studifrancesi.22926

Ce document a été généré automatiquement le 3 août 2021

\section{(c) $($ ) $(9)$}

Studi Francesi è distribuita con Licenza Creative Commons Attribuzione - Non commerciale - Non opere derivate 4.0 Internazionale. 


\title{
MARILYN MALLIA, Présence du roman gothique anglais dans les premiers romans de George Sand
}

\author{
Annabelle M. Rea
}

\section{RÉFÉRENCE}

MARILYN MALLIA, Présence du roman gothique anglais dans les premiers romans de George Sand, Paris, Classiques Garnier, 2018, 281 pp.

1 En 2015, la George Sand Association a attribué son prix de la meilleure thèse - The George Sand Association Memorial Prize - à Marilyn Mallia pour son étude, L'Importance du roman gothique anglais dans les premiers romans de George Sand. Quelques années plus tard, cette thèse de l'Université de Southampton, écrite sous la direction de la professeure Mary Orr, est devenue Présence du roman gothique anglais dans les premiers romans de George Sand, un ouvrage encore plus brillant que la thèse. L'ouvrage est publié par Garnier, maison déjà réputée parmi les sandiens pour sa publication de 25 volumes de la correspondance de George Sand, éditée par le tant respecté Georges Lubin (c'est Du Lérot qui a publié le $26^{\mathrm{e}}$ volume).

2 Les sandiens ont toujours reconnu, bien avant les travaux de Marilyn Mallia, «l'importance» du roman gothique anglais pour Sand, mais personne n'en avait révélé la profondeur dans toutes ses ramifications. Mallia commence par un survol détaillé des caractéristiques de la tradition gothique des différents auteurs, femmes et hommes (1760-1820), mais surtout de la plus importante d'entre eux pour l'œuvre de George Sand, Ann Radcliffe. La bibliographie de plus de six pages sur cette tradition, comportant des titres en anglais ainsi qu'en français, révèle l'étendue des connaissances de Mallia et le sérieux de son travail de synthèse. Mais dans cette bibliographie de plus de vingt pages en tout, Mallia consacre presque la moitié à des «études critiques sur George Sand», car tel est l'objectif de son ouvrage: l'examen des 
«stratégies» sandiennes empruntées au genre anglais. Bien que l'auteure mentionne de nombreux textes sandiens, voici le corpus auquel elle se limite pour ses analyses détaillées: Indiana (1832), Valentine (1832), Mauprat (1837), les deux versions de Lélia (1833 et 1839), Consuelo (1842) et La Comtesse de Rudolstadt (1843).

3 La première stratégie sandienne étudiée par Mallia est celle du dédoublement des héroïnes, phénomène, certes, remarqué par beaucoup de critiques, mais sans la riche contextualisation offerte ici. Mallia analyse, par exemple, les sœurs de lait, Indiana et Noun, mais en soulignant pour cette dernière, non la femme subalterne «dénuée de tout pouvoir» (p. 70), mais celle qui «essaie de se forger un espace identitaire au sein de la relation amoureuse» (p. 72). En fait, ici, Mallia débat avec la critique sandienne citée le plus souvent dans son ouvrage, Isabelle Naginski, qui a caractérisé Noun comme «triplement réduite au silence» (p.70, n. 77). La discussion du dédoublement se prolonge pour traiter des personnages féminins de générations différentes, comme Wanda, l'initiatrice, et Consuelo. Cette analyse se diversifie dans Mauprat pour explorer le renversement des rôles sexuels habituels et la création d'un «nouveau "contrat social" du couple idéal» (p. 174).

On pourrait continuer longtemps ainsi à énumérer les questions passionnantes soulevées par Mallia: le pouvoir d'initiative et d'action de la femme, les épreuves, la claustration volontaire et l'initiation, par exemple. Pourtant, on pourrait facilement se convaincre de la nécessité de lire l'étude de Marilyn Mallia en consultant l'outil pédagogique qu'elle a créé pour aider ses élèves (elle enseigne actuellement à l'Université de Malte) à visualiser le schéma gothique de Consuelo: www.gothicconsuelo.appspot.com. Il faut donc lire Présence du roman gothique dans les premiers romans de George Sand pour son érudition, sa vision comparative, son renouvellement des œuvres analysées - les plus étudiées de Sand, d'ailleurs - ou pour le courage dont fait preuve l'auteure dans ses jugements critiques (par exemple, une lecture «réductrice» (p.139) du roman gothique anglais ou «une étrange omission» (p. 61) du «monument» qu'est devenu l'ouvrage de Sandra Gilbert et Susan Gubar, The Madwoman in the Attic), ou pour son style précis et éloquent, ses traductions élégantes. Sa lecture est indispensable. 